\title{
Non-Clinical Postpairing Trial Phase
}

National Cancer Institute

\section{Source}

National Cancer Institute. Non-Clinical Postpairing Trial Phase. NCI Thesaurus. Code C124605.

The period of time in a non-clinical study that occurs after the paired subjects are separated. This includes males and non-confirmed mated females. 